\title{
Methyleugenol Potentiates Central Amygdala GABAergic Inhibition and Reduces Anxiety
}

\author{
Yan-Mei Liu, ${ }^{1}$ Hui-Ran Fan, ${ }^{1}$ Shining Deng, Tailin Zhu, Yuhua Yan, Wei-Hong Ge, \\ (1)Wei-Guang $\mathrm{Li}$, and (D)Fei Li
}

\begin{abstract}
Developmental and Behavioral Pediatric Department, Ministry of Education-Shanghai Key Laboratory for Children's Environmental Health, Shanghai Institute for Pediatric Research, Xinhua Hospital Affiliated to Shanghai Jiao Tong University School of Medicine, Shanghai (Y.-M.L., H.-R.F., S.D., T.Z., Y.Y., F.L.); Collaborative Innovation Center for Brain Science, Department of Anatomy and Physiology, Shanghai Jiao Tong University School of Medicine, Shanghai (Y.-M.L., H.-R.F., W.-G. L.); and Department of Chinese Materia Medica, College of Pharmaceutical Science, Zhejiang Chinese Medical University, Hangzhou (Y.-M.L., H.-R.F., W.-H.G.), People's Republic of China
\end{abstract}

Received May 30, 2018; accepted October 17, 2018

\section{ABSTRACT}

The central amygdala (CeA) plays a critical role in the expression of emotional behaviors, including pathologic anxiety disorders. The present study demonstrated that GABAergic inhibition in $\mathrm{CeA}$ was significantly increased by methyleugenol (ME), a natural constituent isolated from the essential oils of several plants. The electrophysiologic recordings showed that ME increased both tonic and miniature inhibitory postsynaptic GABAergic currents in $\mathrm{CeA}$ slices, especially the tonic currents, while the miniature excitatory postsynaptic currents were not affected. In the fearinduced anxiety animal model, both intraperitoneal injection or $\mathrm{CeA}$-specific infusion of $\mathrm{ME}$ reduced the anxiety-like behaviors in mice, likely by facilitating the activation of A-type GABA receptors $\left(G A B A_{A} R s\right)$. These results reveal that $G A B A_{A} R$ in the $\mathrm{CeA}$ can be a potential therapeutic target for the treatment of anxiety and that ME is capable of enhancing the GABAergic inhibition in $\mathrm{CeA}$ neurons for the inhibition of neuronal excitability.

\section{Introduction}

Anxiety disorders are highly prevalent and cause an enormous health burden on society, but few effective therapeutics have emerged in the past two decades. Anxiety is characterized by sustained arousal, vigilance, and apprehension, mediated by multiple brain areas such as the basolateral amygdala, the bed nucleus of the stria terminalis, medial prefrontal cortex (mPFC), and central amygdala (CeA) (Botta et al., 2015; Tovote et al., 2015). Neuroimaging studies have revealed disturbances in the limbic circuits composed of the mPFC, hippocampus, and amygdala under pathophysiologic conditions (Etkin et al., 2009), implying that the impairments in the inhibitory influence of the hippocampus and mPFC lead

This study was supported by grants from the National Natural Science Foundation of China [Grants no. 81571031, 81701334, 81771214, 81761128035, and 81781220701], the Shanghai Committee of Science and Technology [Grants no. 17XD1403200,18DZ2313505, 14DJ1400204, and 18QA1402500], the Shanghai Municipal Education Commission [Research Physician Project: 20152234], the Shanghai Municipal Commission of Health and Family Planning [Grants no. 2017ZZ02026, 2017EKHWYX-02, GDEK201709, and 2018BR33], and the Shanghai Shen Kang Hospital Development Center [Grant no. 16CR2025B].

${ }^{1}$ Y.-M.L. and H.-R.F. contributed equally to this work.

https://doi.org/10.1124/jpet.118.250779. to hyperexcitability of the amygdala, which is closely related to anxiety (Etkin et al., 2009; Kim et al., 2011). Therefore, characterizing the neuronal mechanisms in the amygdala that regulate anxiety behaviors would be helpful in identifying the putative abnormal substrates in the pathologic environment.

Anxiety can be regulated by interference with GABAergic inhibition in the amygdala (Roberto et al., 2008; Tasan et al., 2011). There is evidence that CeA microcircuits are not only important for fear but also necessary for anxiety (Tovote et al., 2015 ) and that the tonic inhibition within the CeA circuits is altered in animal models of chronic anxiety disorder (Botta et al., 2015). Therefore, looking for novel compounds to restore the tonic inhibition mediated by A-type GABA receptors $\left(\mathrm{GABA}_{\mathrm{A}} \mathrm{Rs}\right)$ may offer novel strategies for the treatment of anxiety disorders.

The synaptic or extrasynaptic localization of $\mathrm{GABA}_{A} \mathrm{RS}_{\mathrm{S}}$ within a neuron confers the phasic and tonic forms of GABAergic inhibition, respectively. Phasic inhibition is generated by the rapid, transient activation of synaptic $\mathrm{GABA}_{\mathrm{A}} \mathrm{Rs}$ by presynaptic GABA release; tonic inhibition is generated by the persistent activation of extrasynaptic $\mathrm{GABA}_{\mathrm{A}} \mathrm{Rs}$ (Wlodarczyk et al., 2013). Compared with phasic inhibition, $\mathrm{GABA}_{\mathrm{A}} \mathrm{R}$-mediated tonic inhibition plays a crucial role in

ABBREVIATIONS: ACSF, artificial cerebrospinal fluid; CeA, central amygdala; CNS, central nervous system; CS, conditional stimulus; D-APV, D-2amino-5-phosphonopentanoic acid; CNQX, 6-cyano-7-nitroquinoxaline-2,3-dione; EPM, elevated plus maze; GABA $A_{A}$, A-type GABA receptor; HC030031, 2-(1,3-dimethyl-2,6-dioxopurin-7-yl)- $N$-(4-propan-2-ylphenyl)acetamide; HEK, human embryonic kidney; me, methyleugenol; mEPSC, miniature excitatory postsynaptic current; mIPSC, miniature inhibitory postsynaptic current; mPFC, medial prefrontal cortex; PTX, picrotoxin; SR95531, 2-(3-carboxypropyl)-3-amino-6-(4-methoxyphenyl)pyridazinium bromide; TRPA1, transient receptor potential ankyrin 1 (TRPA1); TTX, tetrodotoxin; US, unconditional stimulus. 
A

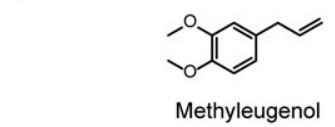

(1,2-dimethoxy-4-prop-2-en-1ylbenzene, ME)
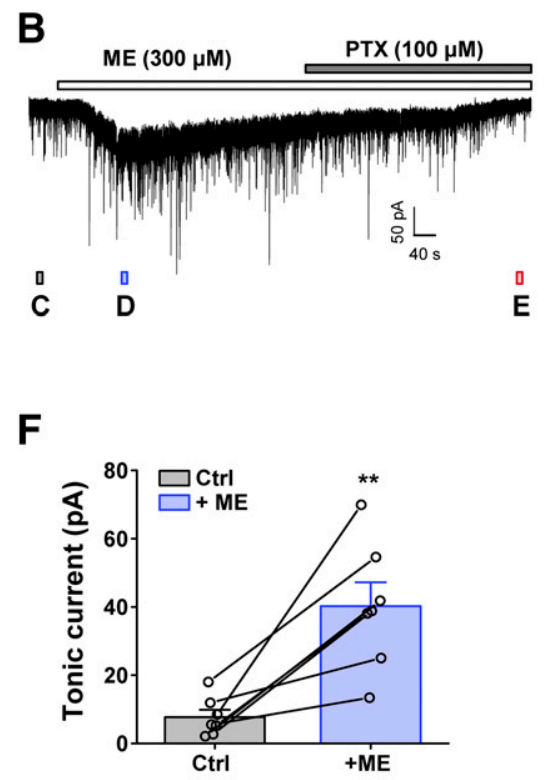
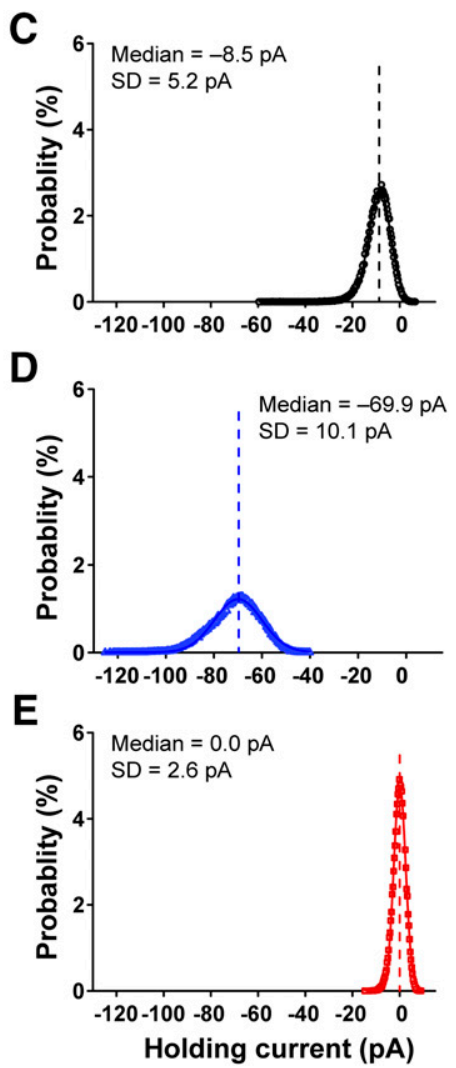

Fig. 1. ME enhances the tonic GABAergic current in $\mathrm{CeA}$ slices. (A) Chemical structure of ME. (B) Representative current traces from CeA neurons in the absence or presence of ME $(300 \mu \mathrm{M})$. The tonic current was revealed by the application of $100 \mu \mathrm{M}$ PTX. (C-E) All-point histograms of 10-second traces at time points $\mathrm{C}, \mathrm{D}$, and $\mathrm{E}$, as indicated in B (lower). The histograms were fitted with single Gaussians, and the median and S.D. were determined. The baseline level (in the presence of PTX) was set to zero during the recording period (E). (F) Pooled data of basal and $\mathrm{ME}$-enhanced tonic currents in individual CeA neurons. From four mice, $n=7$ neurons. $* * P<0.01$, compared with the control (Ctrl), paired Student's $t$ test. modulating neuronal excitability and is associated with several neurologic diseases such as stroke (Brickley and Mody, 2012), epilepsy (Houser and Esclapez, 2003; Brickley and Mody, 2012), and anxiety (Botta et al., 2015). Therefore, extrasynaptic $\mathrm{GABA}_{\mathrm{A}} \mathrm{Rs}_{\mathrm{s}}$ may serve as a therapeutic target for the treatment of these diseases.

Methyleugenol (1,2-dimethoxy-4-prop-2-en-1-ylbenzene, ME; Fig. 1A) is a natural constituent of several aromatic plants such as Myristica fragrans, Ocimum basilicum, Pimenta officinalis, Cinnamomum oliveri, Thapsia villosa, and their essential oil fractions (De Vincenzi et al., 2000). Ding et al. (2014) showed that ME can inhibit the activity of hippocampal neurons as well as activate the $\alpha_{1}-\beta_{2}-\gamma_{2}$ or $\alpha_{5}-\beta_{2}-\gamma_{2} \mathrm{GABA}_{\mathrm{A}} \mathrm{Rs}$ expressed in human embryonic kidney (HEK) 293T cells, which may account for its pharmacologic effects on the central nervous system (CNS). Indeed, ME was recently reported to counteract anorexigenic signals for feeding regulation in association with GABAergic phasic inhibition in the CeA (Zhu et al., 2018). Other potential cellular targets for ME within the CNS include voltage-gated sodium channels (Wang et al., 2015) and transient receptor potential ankyrin 1 (TRPA1) channels (Moon et al., 2015).

The mechanisms underlying the effect of $\mathrm{ME}$ on brain activity and its pharmacologic effects on CNS have yet to be fully established. Whether ME can affect the tonic inhibition of $\mathrm{CeA}$ neurons by agitating $\mathrm{GABA}_{\mathrm{A}} \mathrm{Rs}$ or regulating anxiety behaviors by regulating the GABAergic inhibition of $\mathrm{CeA}$ neurons is as yet unknown.

\section{Materials and Methods}

Animals. All behavioral measurements were performed in adult, unrestrained, awake male C57BL/6J mice (8-12 weeks old), which were obtained from Shanghai Slac Laboratory Animal Company Limited (Shanghai, People's Republic of China). The animal procedures were approved by the animal ethics committee of Shanghai Jiao Tong University School of Medicine in Shanghai, People's Republic of China. All efforts were made to reduce the number of animals used and minimize their suffering.

The mice were housed under standard laboratory conditions (12hour light/dark cycle, temperature $22-26^{\circ} \mathrm{C}$, air humidity $55 \%-60 \%$ ) with food and water ad libitum. All the animal procedures were carried out according to the guidelines for the Care and Use of Laboratory Animals of Shanghai Jiao Tong University School of Medicine, and approved by the Institutional Animal Care and Use Committee (Department of Laboratory Animal Science, Shanghai Jiao Tong University School of Medicine) (Policy Number DLAS-MPANIM. 01-05).

Drugs. All drugs were purchased from Sigma-Aldrich (St. Louis, MO). In the electrophysiologic experiments, the final concentration of dimethylsulfoxide was $<0.1 \%$ and ineffective on the GABAergic currents. Other drugs were solubilized in ion-free water and diluted to the final concentrations in the standard external solution before use or solubilized directly in the standard external solution.

Slice Electrophysiology. Experiments were performed on $300 \mu \mathrm{m}$ transverse CeA slices from 8- to 12-week-old C57BL/6J mice. Briefly, after decapitation, the mouse brains were removed immediately and placed in a well-oxygenated $\left(\begin{array}{llll}95 & \mathrm{O}_{2} / 5 \% & \mathrm{CO}_{2}\end{array}\right)$ ice-cold artificial cerebrospinal fluid (ACSF) containing $126 \mathrm{mM} \mathrm{NaCl}$, $2.5 \mathrm{mM} \mathrm{KCl}, 10 \mathrm{mM}$ D-glucose, $2 \mathrm{mM} \mathrm{MgSO}_{4}, 2 \mathrm{mM} \mathrm{CaCl}_{2}, 1.25 \mathrm{mM}$ $\mathrm{NaH}_{2} \mathrm{PO}_{4}$, and $26 \mathrm{mM} \mathrm{NaHCO}_{3}$. Slices were cut from the CeA with a Vibratome (VT 1000S; Leica, Wetzlar, Germany) and were incubated at $30^{\circ} \pm 1^{\circ} \mathrm{C}$ in oxygenated ACSF for at least 1 hour before transfer to a recording chamber. The CeA slices were continuously perfused with well-oxygenated ACSF at $30 \pm 1^{\circ} \mathrm{C}$ during all the electrophysiologic studies.

Whole-cell patch clamp recordings were made from CeA neurons controlled by an infrared-differential interference contrast video 
microscope (BX51WI; Olympus, Tokyo, Japan). The holding potential was $-70 \mathrm{mV}$. The patch pipettes had open-tip resistances of 3-5 $\mathrm{M} \Omega$ when filled with an intracellular solution that contained $110 \mathrm{mM}$ $\mathrm{CsCl}, 30 \mathrm{mM}$ potassium gluconate, $1.1 \mathrm{mM}$ EGTA, $10 \mathrm{mM}$ HEPES, $0.1 \mathrm{mM} \mathrm{CaCl} 2,4 \mathrm{mM} \mathrm{Mg-ATP}, 0.3 \mathrm{mM} \mathrm{Na-GTP}$ (pH adjusted to 7.3 with $\mathrm{CsOH}, 280 \mathrm{mOsm}$ )

For the recordings of tonic and phasic GABAergic currents, drugs were applied to the bath by a gravity-driven perfusion system. Except where otherwise indicated, for the recording of tonic and miniature inhibitory postsynaptic currents (mIPSCs), tetrodotoxin (TTX, $1 \mu \mathrm{M}$ ), D-2-amino-5-phosphonopentanoic acid (D-APV, $50 \mu \mathrm{M}$ ), and 6-cyano7-nitroquinoxaline-2,3-dione (CNQX, $20 \mu \mathrm{M}$ ) were added to the bath. The tonic GABA currents were demonstrated by administering picrotoxin (PTX, $100 \mu \mathrm{M}$ ).

For all the patch-clamp recordings, only one cell was recorded per slice to avoid contamination from prior drug applications. The MiniAnalysis 6.0.1 program (Synaptosoft, Decatur, GA) was used to analyze the mIPSC and mEPSC. The amplitude threshold for event detection was set to $10 \mathrm{pA}$ for mIPSC or mEPSC, respectively; the other parameters used were the defaults. Each event recorded in each cell was characterized by the following parameters: frequency, amplitude, rise time, and decay time, which were calculated using the MiniAnalysis 6.0.1 program.

Measurement of Tonic Current. The tonic current was measured as described elsewhere (Zhang et al., 2008; Huang et al., 2013) with minor modifications. The baseline was calculated by generating all point histograms of 10 -second epochs (see Fig. 1, C-E) at 1 minute before drug application, more than 5 minutes after drug application but just before the treatment with PTX, and more than 5 minutes after PTX application until fully stabilization of baseline, respectively. A Gaussian distribution was fitted to the histogram at these periods. Based on using the median of the fitted Gaussian as zero, the mean of the fitted Gaussians at different periods was then calculated as tonic currents under different conditions, respectively.

Fear Conditioning. The fear conditioning protocol was performed out as described elsewhere with minor modifications (Botta et al., 2015). The conditioning boxes and the floor were cleaned before and after each session using $75 \%$ ethanol, respectively. Before fear conditioning, the animals were handled for 5 minutes for 3 days consecutively. On day 1 , the mice were brought to the training room, placed individually in the conditioning boxes for 20 minutes, and returned to their home cages. Fear conditioning was performed on day 2 by pairing the conditional stimulus (CS: a tone, $85 \mathrm{~dB}, 4000 \mathrm{~Hz}$, 30 seconds) with an unconditional stimulus (US: 2 -second foot shock, $0.5 \mathrm{~mA}$ ), for five CS-US pairings (intertrial interval $20-180$ seconds) in the CS-US group. The onset of the US coincided with the offset of the CS, and the US was delivered immediately after the CS. The CS-only group received a similar procedure but without the foot shock.

Surgical Procedures and Drug Microinjection. The animals were anesthetized with $1 \%$ pentobarbital sodium and placed in a stereotaxic apparatus (RWD Life Science, Shenzhen, People's Republic of China), followed by bilateral implantation using a 26-gauge guide cannula aimed at $1 \mathrm{~mm}$ above the CeA region on each side at the following coordinates: anteroposterior, $-1.2 \mathrm{~mm}$; lateral, $\pm 2.4 \mathrm{~mm}$; dorsoventral, $-3.5 \mathrm{~mm}$. The cannulas were positioned in place with acrylic dental cement and were secured with skull screws. A stylus was placed in the guide cannula to prevent clogging.

The animals were allowed to recover from surgery for 2 weeks before experimental manipulations. Mice were handled and habituated to the infusion procedure several days before drug injection. During drug infusion, the mice were briefly head restrained while the stainless-steel obturators were removed and the injection cannulas (30-gauges; RWD Life Science) were inserted into guide cannulas. The injection cannulas protruded $1.00 \mathrm{~mm}$ from the tips of guide cannulas. The infusion cannula was connected via PE20 tubing to a microsyringe driven by a microinfusion pump (KDS 310; KD Scientific, Holliston, MA).

Vehicle only ( $0.5 \mu \mathrm{l}$ ACSF per side) or ME ( $1 \mu \mathrm{g}$ in $0.5 \mu \mathrm{l}$ per side in ACSF) was infused bilaterally into the target brain areas at a flow rate of $0.15 \mu \mathrm{l}$ per minute. After the drug injection was finished, the injection cannulas were left in place for 2 minutes to allow the solution to diffuse from the cannula tip. The stainless-steel obturators were subsequently reinserted into guide cannulas, and the mice were returned to their home cage for 30 minutes before the behavioral tests.

The injection sites were examined at the end of the experiments and were mapped postmortem by sectioning the brain ( $30 \mu \mathrm{m}$ coronal $)$ and performing cresyl violet staining (in $100 \mathrm{ml}: 0.5 \mathrm{~g}$ of cresyl, $20 \mathrm{ml}$ of $100 \%$ ethanol, and $1.5 \mathrm{ml}$ of glacial acetic acid, $\mathrm{pH} 3.5-3.7)$. The animals with an incorrect diffusion scope were excluded from the data analysis.

Elevated Plus Maze. The elevated plus maze (EPM), which was made of black plastic material, consisted of four arms (two open arms without walls and two enclosed arms with $15.25-\mathrm{cm}$ high walls) that were $30 \mathrm{~cm}$ in length and $5 \mathrm{~cm}$ in width. Each arm of the maze was attached to sturdy metal legs such that it was elevated above the floor. A digital camera was set directly above the apparatus. Images were captured at a rate of $5 \mathrm{~Hz}$ and quantified using the Ethovision video tracking system (Noldus Information Technology, Wageningen, Netherlands).

The tests were conducted under dim light during the light phase of the cycle (between 07:00 AM and 07:00 PM). The maze was cleaned with $75 \%$ ethanol between tests. The testing room was quiet and dimly lit, and the animals were habituated to this room for at least 60 minutes before starting the tests. The animals were placed individually in the center of the maze facing the open arms, and their behavior was recorded for 5 minutes. After each trial, the entire maze was cleaned, and the animal returned to the home cage. The time spent on the open and closed arms was recorded and analyzed.

Statistical Analysis. All results were presented as mean \pm S.E.M. Unpaired or paired Student's $t$ tests and two-sample KolmogorovSmirnov tests were used for comparisons as indicated in the figure legends, where $P<0.05, P<0.01$, and $P<0.001$ were considered statistically significant differences.

\section{Results}

ME Enhances the Tonic GABAergic Inhibition in CeA Slices. A previous study (Ding et al., 2014) showed that $\mathrm{ME}$ (Fig. 1A) acted as a novel agonist of $\mathrm{GABA}_{\mathrm{A}} \mathrm{Rs}_{\mathrm{s}}$ that could inhibit the activity of hippocampal neurons and cause the activation of $\alpha_{1}-\beta_{2}-\gamma_{2}$ or $\alpha_{5}-\beta_{2}-\gamma_{2} \mathrm{GABA}_{\mathrm{A}} \mathrm{Rs}$ expressed in HEK-293T cells. To further establish the mechanisms underlying $\mathrm{ME}$ on brain activity and identify new pharmacologic effects on the CNS, we measured the tonic GABAergic currents in CeA slices. The application of PTX $(100 \mu \mathrm{M})$ under intracellular conditions of high $\mathrm{Cl}^{-}$concentration leads to the display of slight basal inward tonic currents (about $-8 \mathrm{pA}$ ) by most CeA neurons (Fig. 1B). TTX $(1 \mu \mathrm{M})$ was added to the bath to block the action potential-dependent GABA release and to reduce any random baseline current fluctuations.

Subsequently, we examined whether ME could enhance this basal tonic current. The superfusion of $\mathrm{ME}(300 \mu \mathrm{M})$ for $5-10$ minutes resulted in a slowly developing and reversible inward shift in the holding current (i.e., tonic current) of $-40.2 \pm$ $7.0 \mathrm{pA}$ in CeA neurons ( $n=7, P<0.01$, paired Student's $t$ test) (Fig. 1, C-F). The ME-enhanced tonic currents could be blocked by the application of $100 \mu \mathrm{M}$ PTX (Fig. 1B), suggesting that these tonic currents were mediated by $\mathrm{GABA}_{\mathrm{A}} \mathrm{Rs}$. ME-induced potentiation of the tonic current was observed in every tested cell (Fig. 1F), indicating that the facilitation of endogenous tonic GABAergic inhibition by ME was common among the CeA slices.

ME Enhances Tonic Inhibition Irrespective of Action Potential Blockade. We also measured GABAergic tonic inhibition in CeA neurons without action potential blockade-namely, 
A

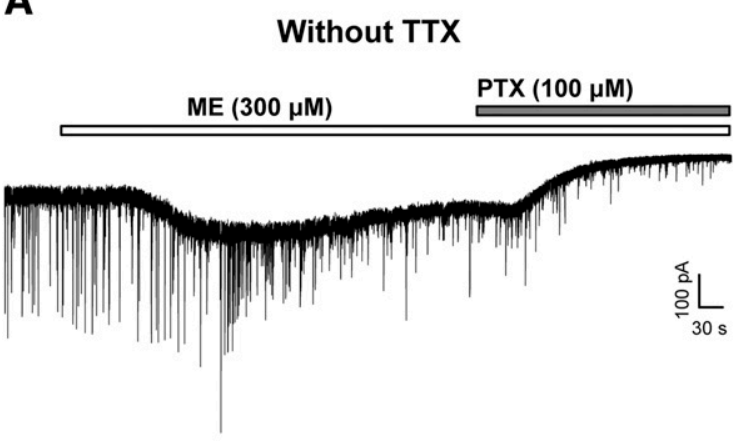

C

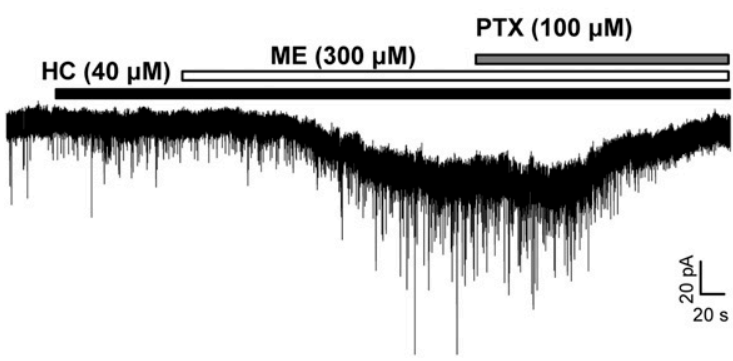

B

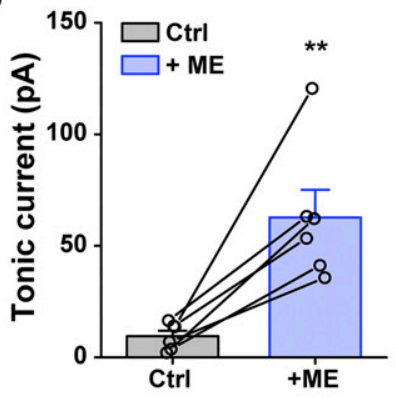

D

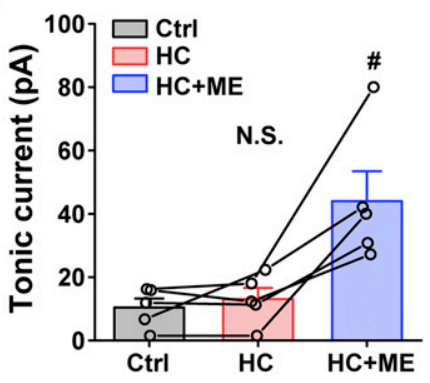

Fig. 2. ME enhances tonic inhibition irrespective of action potential blockade and independent of TRPA1 channel activation. (A and $\mathrm{B}$ ) Effect of $\mathrm{ME}$ on tonic inhibition is independent of action potential blockade. (A) Representative images showing the effect of $\mathrm{ME}(300 \mu \mathrm{M})$ on tonic inhibition in the absence of TTX. (B) Pooled data shown in A. From four mice, $n=6$ neurons. $* * P<0.01$, compared with the control (Ctrl), paired Student's $t$ test. (C and D) Effect of ME on tonic inhibition is independent of TRPA1 channel activation. (C) Representative images showing the effect of $\mathrm{ME}(300 \mu \mathrm{M})$ on tonic inhibition in the presence of HC-030031 (40 $\mu \mathrm{M})$. (D) Pooled data shown in C. From five mice, $n=5$ neurons. N.S., no significant difference, control (Ctrl) vs. $\mathrm{HC} ;{ }^{\#} \mathrm{P}<0.05, \mathrm{HC}$ vs. $\mathrm{HC}+\mathrm{ME}$, paired Student's $t$ test. in the absence of TTX (1 $\mu \mathrm{M})$. As shown in Fig. 2, A and B, application of $\mathrm{ME}(300 \mu \mathrm{M})$ further increased the membrane current. Both the basal and ME-enhanced tonic currents were blocked by application of PTX (100 $\mu \mathrm{M})$, suggesting that the tonic currents were mediated by $\mathrm{GABA}_{\mathrm{A}} \mathrm{Rs}_{\mathrm{s}}$. Quantification of the amplitude of basal and ME-potentiated GABAergic tonic currents in the absence (Fig. 2B) or presence of TTX (Fig. 1F) yielded no significant difference (basal, $-9.5 \pm$ $2.5 \mathrm{pA}$ vs. $-7.7 \pm 2.1 \mathrm{pA} ; \mathrm{ME}:-62.7 \pm 12.4 \mathrm{pA}$ vs. $-40.2 \pm$ $7.0 \mathrm{pA}, n=6$ and 7 , respectively, in the absence vs. presence of TTX, both $P>0.05$, unpaired Student's $t$ test; Fig. 1F; Fig. 2B). Thus, ME enhances the tonic inhibition of CeA neurons largely irrespective of action potential blockade-in other words, not relying on the action potential-dependent GABA release.

ME Enhances Tonic GABAergic Inhibition Independently of TRPA1 Activation. A previous study showed that ME is an agonist of the TRPA1 channel (Moon et al., 2015). In addition, TRPA1 channels regulate the $\mathrm{Ca}^{2+}$ concentrations of the resting astrocyte. This in turn decreases interneuron inhibitory synapse efficacy by reducing GABA transport through GABA transport-3, which consequently elevates extracellular GABA and increases tonic inhibition (Shigetomi et al., 2011). To determine whether the TRPA1 channel contributes to the tonic inhibition in CeA slices, we pretreated the slices with 2-(1,3-dimethyl-2,6-dioxopurin-7yl)- $N$-(4-propan-2-ylphenyl)acetamide (HC-030031, $40 \mu \mathrm{M})$, a TRPA1 channel antagonist (Fig. 2C).

As a result, the tonic currents increased by $\mathrm{ME}$ in the presence of HC-030031 (40 $\mu \mathrm{M})$ were significant, and they did not differ when compared with the currents observed under control conditions $(-44.0 \pm 9.4$ vs. $-40.2 \pm 7.0 \mathrm{pA} ; n=5$ and 7 , respectively, $P>0.05$, unpaired Student's $t$ test) (Fig. $1 \mathrm{~F}$; Fig. 2, C and D). These results indicated that TRPA1 channels do not mediate the effect of ME on tonic GABAergic inhibition in CeA neurons.
ME-Increased Tonic Inhibition Is Insensitive to Competitive $\mathbf{G A B A}_{\mathbf{A}} \mathbf{R}$ Antagonist. Previous studies showed that tonic $\mathrm{GABA}_{\mathrm{A}} \mathrm{R}$-mediated conductance in $\mathrm{CeA}$ could be blocked by PTX $(100 \mu \mathrm{M})$ but not by the selectively competitive GABA $\mathrm{R}$ antagonist SR-95531 [2-(3-carboxypropyl)3-amino-6-(4-methoxyphenyl)pyridazinium bromide; 1-50 $\mu \mathrm{M}$ ] (Botta et al., 2015). In the present study, we further explored the effects of ME $(300 \mu \mathrm{M})$-increased tonic inhibition in CeA neurons with SR-95531.

We superfused ME (300 $\mu \mathrm{M})$ and SR-95531 (SR, $10 \mu \mathrm{M})$ in different orders (Fig. 3, A and B). In the presence of ME $(300 \mu \mathrm{M})$, SR-95531 $(10 \mu \mathrm{M})$ did not significantly alter the ME-increased tonic current (Fig. 3, A and B; $n=5, P=0.09$, paired Student's $t$ test). On the other hand, we recorded the effects of ME in the presence of SR-95531 (10 $\mu \mathrm{M}$ ) (Fig. 3, $\mathrm{B}$ and D). Notably, ME increased the tonic current in the presence of SR-95531 (10 $\mu \mathrm{M})(n=5, P<0.05$, paired Student's $t$ test). However, both the effects of tonic current increased by ME were blocked by PTX (100 $\mu \mathrm{M})$ (Fig. 3, A and C).

Taken together, these data imply that ME-increased tonic inhibition in CeA neurons is insensitive to SR-95531, suggesting that SR-95531 unlikely modulates ME binding as it does GABA binding and is competitive at different locations.

ME Enhances GABAergic Phasic Inhibition in CeA Slices. To further explore the functional effects of ME on GABAergic inhibition at the synaptic level, we recorded mIPSCs in CeA slices. ME $(300 \mu \mathrm{M})$ did not exert any significant effect on the frequency, amplitude, or rise time of mIPSCs (Fig. 4, B-D) $(P=0.25, P=0.15, P=0.49$, respectively, $n=7$, paired Student's $t$ test). Moreover, the cumulative distributions of the frequency, amplitude, and rise time of mIPSCs were also unaffected in the CeA neurons (Fig. 4, B-D, $n=7$, all $P>0.05$, two-sample Kolmogorov-Smirnov test).

However, ME significantly increased the decay time of mIPSCs (Fig. 4E) $(8.0 \pm 1.2$ and $14.3 \pm 2.8$ milliseconds before and during ME, respectively, $n=7, P<0.05$, paired 
A

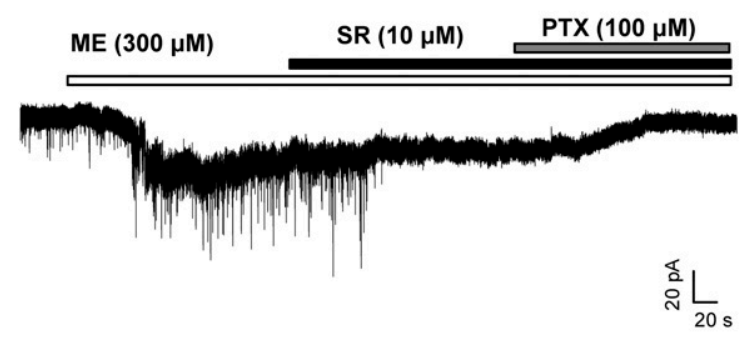

B

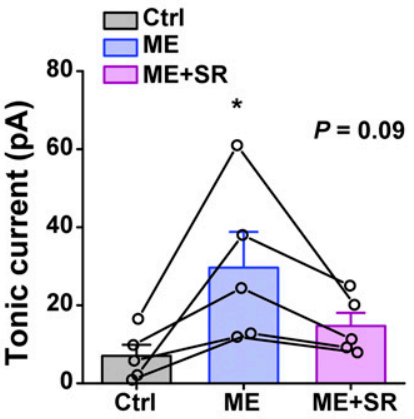

C

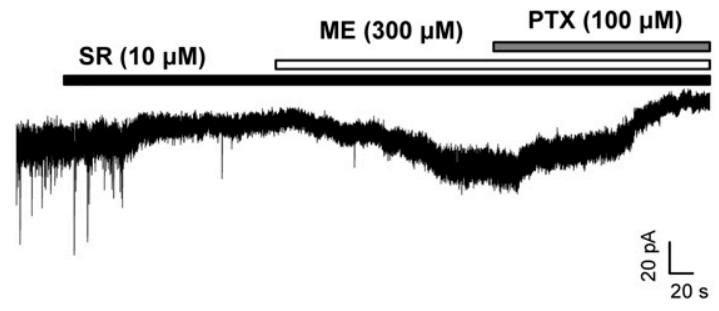

D

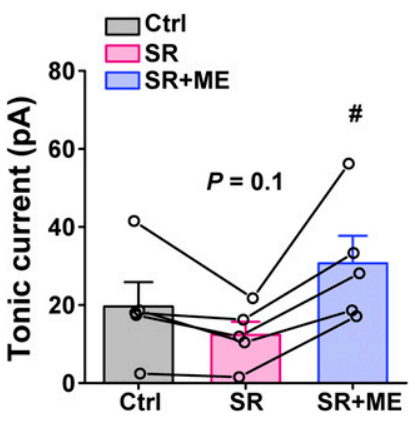

Fig. 3. ME-potentiated tonic inhibition is resistant to SR-95531 in CeA neurons. (A and C) Representative whole-cell current traces recorded from $\mathrm{CeA}$ neurons illustrating the effect of $\mathrm{ME}(300 \mu \mathrm{M})$ on tonic inhibition in the presence of SR-95531 $(10 \mu \mathrm{M})$. Different lines indicate drug application. White: ME. Black: SR-95531. Gray: PTX. (B and D) Pooled data shown in A and C. From four mice for each group, $n=5$ neurons. $* P<0.05 ; P=$ 0.1 , control (Ctrl) vs. ME; $P=0.09 ;{ }^{\#} P<$ 0.05 , SR vs. SR $+\mathrm{ME}$, paired Student's $t$ test.
Student's $t$ test) as well as the cumulative distribution of decay time (Fig. 4E) ( $n=7, P<0.05$, two-sample KolmogorovSmirnov test), suggesting that the postsynaptic $\mathrm{GABA}_{\mathrm{A}} \mathrm{R}$ openings were potentiated by $\mathrm{ME}$, thereby implying an enhancement of phasic GABAergic inhibition by ME in CeA neurons. As a result, ME enhanced the area of the mIPSCs $\left(243.5 \pm 63.0\right.$ and $504.1 \pm 153.9 \mathrm{pA}^{*} \mathrm{~ms}$, before and during ME, respectively, $n=7, P<0.05$, paired Student's $t$ test).

Taken together, these results showed that ME efficiently enhanced phasic GABAergic inhibition in CeA slices.

ME Has No Effect on mEPSCs in CeA Slices. Next, the mEPSCs were measured in CeA slices in the absence or presence of $\mathrm{ME}(300 \mu \mathrm{M})$. As a result, $\mathrm{ME}$ did not exert significant effects on the mEPSC frequency, amplitude, rise time, or decay time nor on the cumulative distributions of frequency, amplitude, rise time, or decay time (Fig. 5, B-E; all $P>0.05, n=5$, paired Student's $t$ test and two-sample Kolmogorov-Smirnov test, respectively). Therefore, the ionic glutamate receptors were not involved in the effects of ME on CeA neurons. A previous study confirmed that ME-activated currents in the hippocampal neurons were not inhibited by the $N$-methyl-D-aspartate (NMDA) or $\alpha$-amino-3-hydroxy-5methyl-4-isoxazolepropionic acid (AMPA) type glutamate receptor antagonists D-APV (20 $\mu \mathrm{M})$ and CNQX $(10 \mu \mathrm{M})(\mathrm{Ding}$ et al., 2014).

ME Produces an Anxiolytic Effect in a Chronic Anxiety Animal Model. According to the earlier electrophysiologic results, ME significantly enhanced both phasic and tonic GABAergic inhibition in neurons throughout the $\mathrm{CeA}$. These findings implicated the modulation of GABAergic activity in the $\mathrm{CeA}$ as a putative cellular substrate for the behavioral changes observed as a result of $\mathrm{ME}$ administration. A previous study showed that the reduced tonic inhibition of CeA neurons could lead to anxiety-like behaviors (Botta et al., 2015). This ME-induced enhancement of GABAergic inhibition within the CeA could potentially modulate the anxiolytic function of this brain region. Thus, we speculated that $\mathrm{ME}$ might reduce anxiety by the potentiation of GABAergic inhibition in the CeA.

We took advantage of the model of fear conditioning to induce pathologic anxiety. The animals were divided into three groups: the CS-only group, the CS-US group, and the CS-US-ME group ( $n=15$ each group) (Fig. 6, A and B). Twenty-four hours after fear conditioning, we tested the level of anxiety in the mice via the EPM, a standard test to evaluate the anxiety level of rodents (Pellow et al., 1985). The animals were acclimatized for 1 hour in the test room; 30 minutes

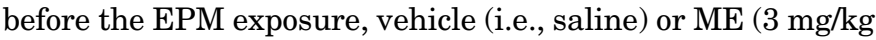
in saline) was intraperitoneally injected into the mice. As a result, although the duration and frequency in the open arm were significantly decreased in the CS-US-vehicle group as compared with the CS-only group (duration: $65.8 \pm 6.0$ vs. 88.7 \pm 8.0 seconds, $P<0.05$, unpaired Student's $t$ test, Fig. 6C; frequency: $17.1 \pm 1.2$ vs. $25.3 \pm 2.0, P<0.01$, unpaired Student's $t$ test, Fig. 6D), those indexes were significantly increased in the CS-US-ME group as compared with the CS-US-vehicle group (duration: $87.8 \pm 7.2$ vs. $65.8 \pm 6.0$ seconds, $P<0.05$, unpaired Student's $t$ test, Fig. 6C; frequency: $22.5 \pm 1.5$ vs. $17.1 \pm 1.2, P<0.01$, unpaired Student's $t$ test, Fig. 6D). However, the distance traveled in the open arm (Fig. 6E) and the total distance in the whole EPM (Fig. 6F) did not vary among these groups. These data suggest that ME possesses a significant pharmacologic effect for antianxiety.

Infusion of ME to CeA Reduces Anxiety Behaviors. The CeA is a crucial region associated with fear and anxiety (Davis et al., 2010; Tye et al., 2011; Botta et al., 2015). The neuronal circuitry of the CeA primarily consists of GABAergic neurons, and the activation of extrasynaptic $\mathrm{GABA}_{\mathrm{A}} \mathrm{Rs}$ is a major factor controlling the excitability of CeA neurons (Farrant and Nusser, 2005; Botta et al., 2015). We explored whether ME could exhibit the pharmacologic effect of 
A
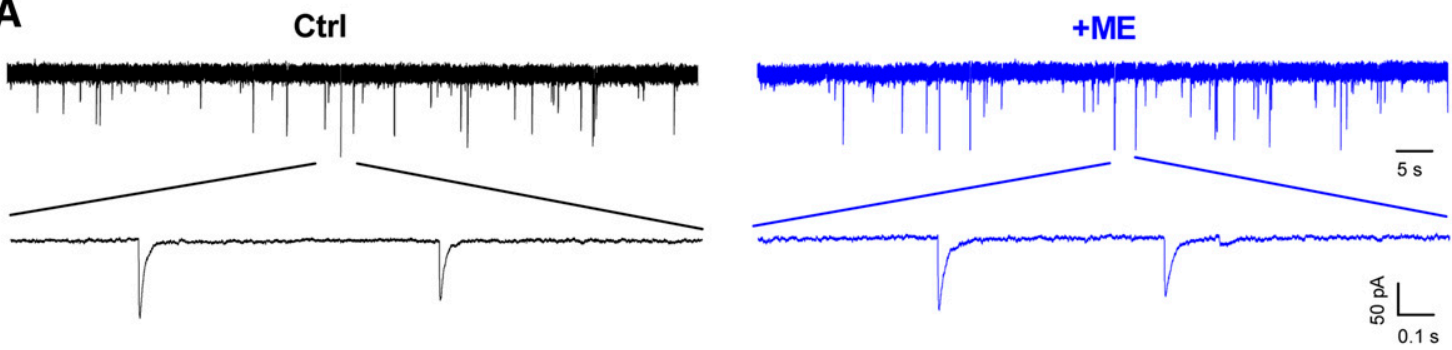

B

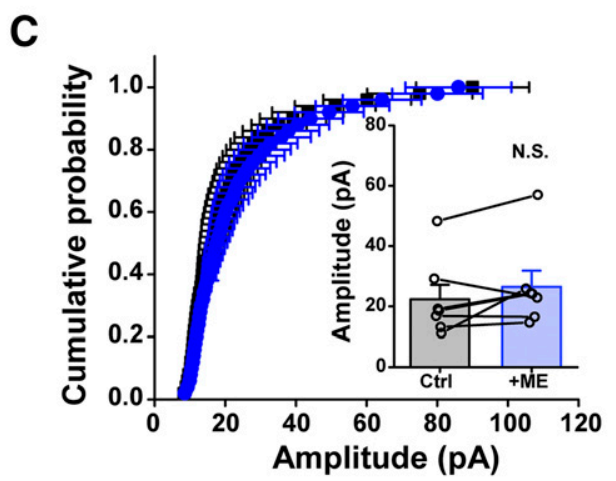

D

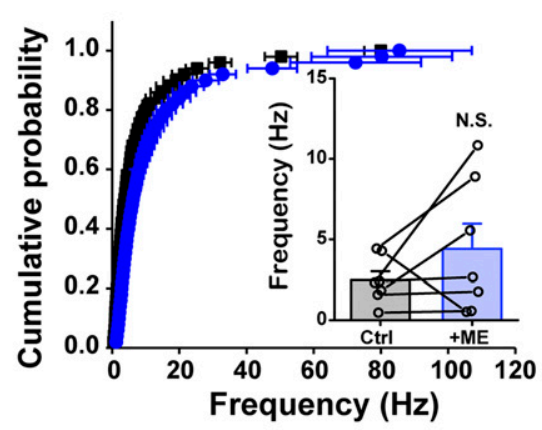

E
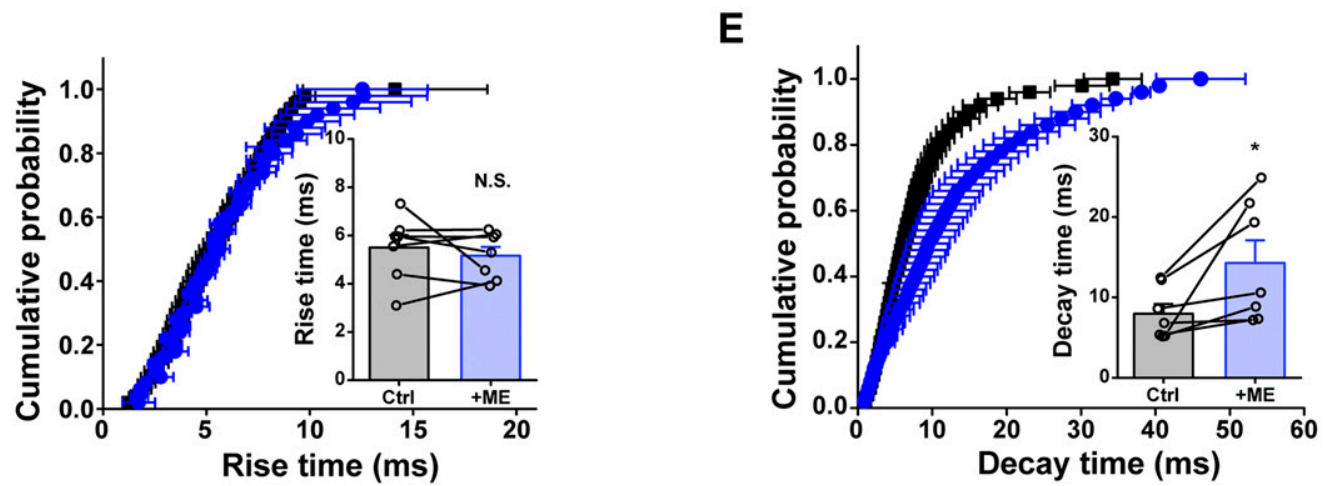

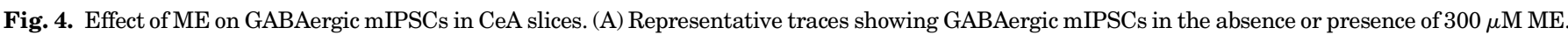

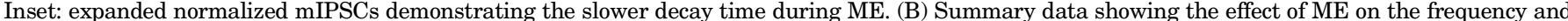

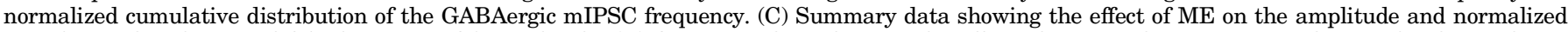

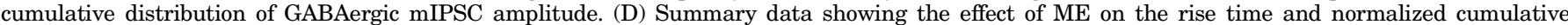

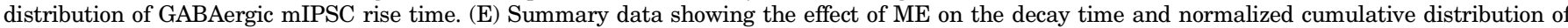

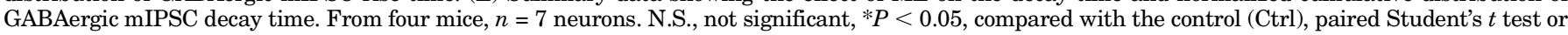
two-sample Kolmogorov-Smirnov test.

antianxiety by directly influencing the excitability of CeA neurons (Fig. 7, A and B).

To focus on the specific brain area, we employed the method of intracranial infusion of $\mathrm{ME}(1 \mu \mathrm{g} / 0.5 \mu \mathrm{l}$ ACSF each side) or vehicle only (0.5 $\mu$ l ACSF each side) into the CeA (intra-CeA infusion, Fig. 7C). Twenty-four hours after fear conditioning, $\mathrm{ME}$ or vehicle was infused into the CeA of mice 30 minutes before EPM exposure. Notably, intra-CeA infusion of ME could reduce the anxiety-like behaviors of mice; the duration and frequency in the open arm were significantly increased as compared with the vehicle group (duration: $119.5 \pm 10.0$ seconds vs. $86.1 \pm 11.1$ seconds, $P<0.05$, unpaired Student's $t$ test, Fig. 7D; frequency: $31.2 \pm 5.0$ vs. $19.4 \pm 1.9, n=9$ each group, $P<0.05$, unpaired Student's $t$ test, Fig. 7E). Meanwhile, the distance that the animal traveled in the open arm (Fig. 7F) and that in the whole EPM (Fig. 7G) was quite similar ( $n=9$ each group, $P<0.05$, unpaired Student's $t$ test) for these two groups.
Taken together, these findings suggest that ME specifically targeted to the CeA can reduce anxiety behaviors, probably via potentiating the GABAergic inhibition there.

\section{Discussion}

In the present study, we observed a slight GABAergic tonic current under basal conditions in CeA slices, which was significantly enhanced by the application of $\mathrm{ME}(300 \mu \mathrm{M})$ (Fig. 1). The increased effect of ME was not affected by the TRPA1 channel antagonist HC-030031 (40 $\mu \mathrm{M})$ (Fig. 2). The tonic current was continually observed in the presence of D-APV and CNQX but not PTX, further proving that the tonic current was mediated by $\mathrm{GABA}_{\mathrm{A}} \mathrm{Rs}$. The ME-increased tonic inhibition in CeA neurons was insensitive to the competitive GABA $_{\mathrm{A}} \mathrm{R}$ antagonist SR-95531 (Fig. 3), suggesting that SR-95531 unlikely modulates ME binding as it does GABA binding and is competitive at different locations. Moreover, $\mathrm{ME}$ 
A

\section{Ctrl}

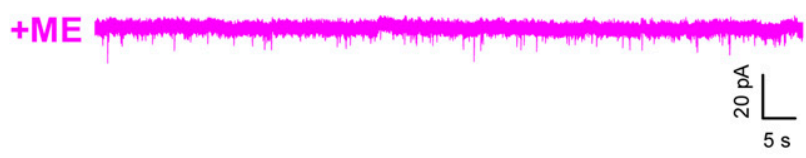

B

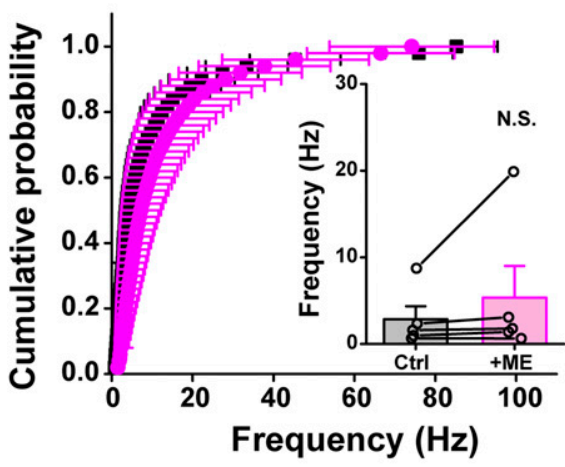

D

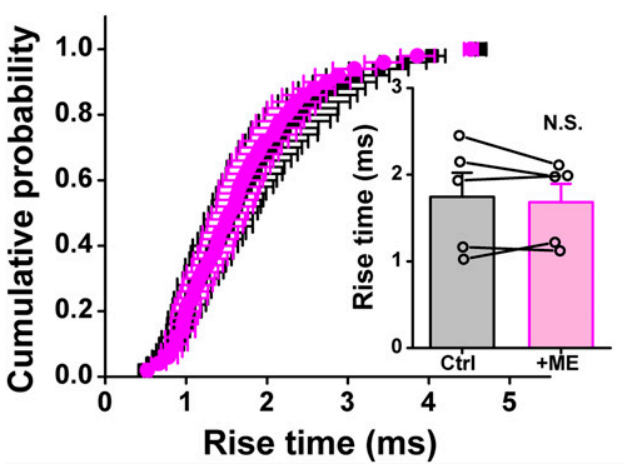

C

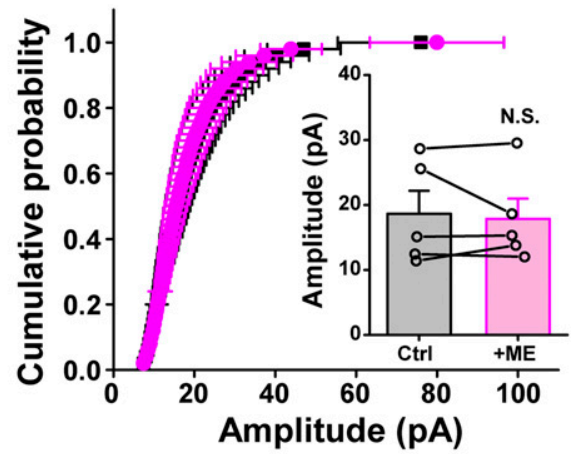

E

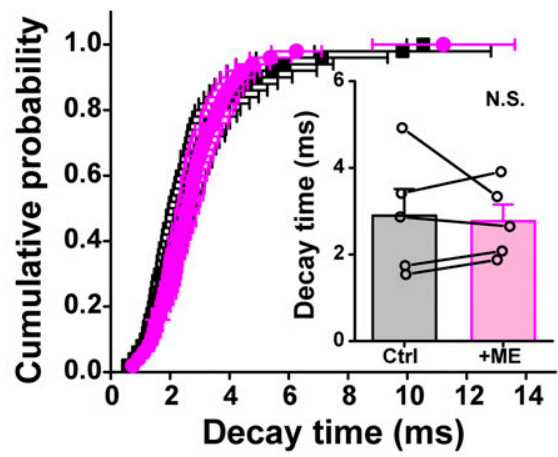

Fig. 5. No effect of ME on glutamatergic mEPSCs in CeA slices. (A) Representative traces showing mEPSCs in the absence or presence of $300 \mu \mathrm{M}$ ME. (B-E) Summary data showing the mEPSCs in the absence or presence of $300 \mu \mathrm{M}$ ME. The frequency and cumulative distribution of frequency (B), amplitude and the cumulative distribution of amplitude (C), rise time and the cumulative distribution of rise time (D), decay time and the cumulative distribution of decay time (E). From four mice, $n=$ 5 neurons. N.S., not significant, compared with the control (Ctrl), paired Student's $t$ test or two-sample Kolmogorov-Smirnov test. enhanced mIPSCs but not mEPSCs in CeA slices (Figs. 4 and 5). Finally, we found that ME reduced anxiety-related behaviors probably by potentiation of GABAergic inhibition in CeA in vivo (Figs. 6 and 7). Taken together, these results identified ME as a novel antianxiety agent targeting GABAergic inhibition in the $\mathrm{CeA}$. In addition, the mechanism underlying the regulation of neural circuits of CeA by GABAergic inhibition strengthens the feasibility of pharmacologic treatment of anxiety disorders.

In general, the phasic and tonic inhibitions mediated by different $\mathrm{GABA}_{\mathrm{A}} \mathrm{R}$ subtypes perform distinct roles in the control of neuronal excitability. Phasic inhibition is usually mediated by $\mathrm{GABA}_{\mathrm{A}} \mathrm{Rs}$ containing $\alpha_{1-3}$ and $\gamma_{2}$ subunits $\left(\alpha_{1-3}-\beta_{\mathrm{x}}-\gamma_{2}\right)$, whereas tonic inhibition is largely but not absolutely mediated by extrasynaptic $\mathrm{GABA}_{\mathrm{A}} \mathrm{Rs}_{\mathrm{s}}$ commonly containing $\alpha_{4-6}$ subunits together with either a $\gamma_{2}$ or $\delta$ subunit $\left(\alpha_{4 / 6}-\beta_{\mathrm{x}}-\delta\right.$ and $\left.\alpha_{5}-\beta_{\mathrm{x}}-\gamma_{2}\right)$ (Farrant and Nusser, 2005). $\mathrm{GABA}_{\mathrm{A}} \mathrm{R}$-mediated tonic inhibition plays a crucial role in the modulation of neuronal excitability and may be associated with several neurologic diseases (Houser and Esclapez, 2003; Brickley and Mody, 2012).

GABAergic transmission in the amygdala controls emotional processes (Tasan et al., 2011) such as fear and anxiety (Botta et al., 2015; Tovote et al., 2015) as well as induces pathologic anxiety traits (Shen et al., 2010). A previous study showed an altered GABAergic transmission in human anxiety disorders (Millan, 2003); benzodiazepines reduce anxiety by modulating $\mathrm{GABA}_{\mathrm{A}} \mathrm{R}$ activation to alter GABAergic transmission. Another study showed that the tonic inhibition in CeA neurons could regulate anxiety-related behaviors (Botta et al., 2015); therefore, the tonic inhibition-mediated by $\mathrm{GABA}_{\mathrm{A}} \mathrm{Rs}_{\mathrm{S}}$ could be a novel target for antianxiety by pharmacologic agents.

In the present study, we found that ME significantly enhanced tonic inhibition (Fig. 1) and prolonged the decay of phasic inhibition, while the frequency, amplitude, and rise time of phasic inhibition were unaltered (Fig. 4) in CeA slices. Thus, ME enhanced the tonic and phasic GABAergic inhibitions in a differential manner; both increased the neuronal inhibition within the CeA synergistically, thereby exhibiting the anxiolytic effect. This phenomenon was in agreement with a previous report (Ding et al., 2014) that had shown that ME activated both $\alpha_{1}-\beta_{2}-\gamma_{2}$ and $\alpha_{5}-\beta_{2}-\gamma_{2}$ GABA $_{\mathrm{A}} \mathrm{Rs}$ in HEK$293 \mathrm{~T}$ cells, representing phasic and tonic inhibition, respectively.

In addition, tonic inhibition is primarily mediated by $\alpha 5$ containing $\mathrm{GABA}_{\mathrm{A}} \mathrm{Rs}_{\mathrm{s}}\left(\alpha 5-\mathrm{GABA}_{\mathrm{A}} \mathrm{Rs}\right)$ or the $\delta$-containing $\mathrm{GABA}_{\mathrm{A}} \mathrm{Rs}$ subtype (Brickley and Mody, 2012). These $\alpha 5-$ $\mathrm{GABA}_{\mathrm{A}} \mathrm{Rs}_{\mathrm{s}}$ are abundant in the CeA (Herman et al., 2013), 


\section{$\underset{\text { or CS only }}{\mathrm{CS}-U S} \stackrel{24 \mathrm{~h}}{\longrightarrow} \begin{gathered}\text { Vehicle or ME } \\ \text { (i.p.) }\end{gathered} \stackrel{30 \mathrm{~min}}{\longrightarrow}$ EPM}

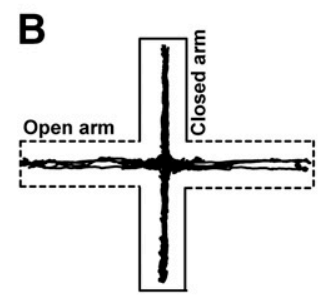

CS only

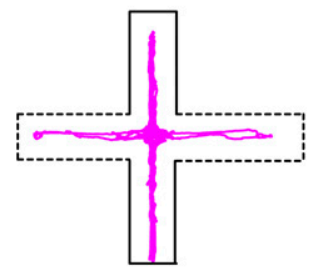

CS-US-Ctrl

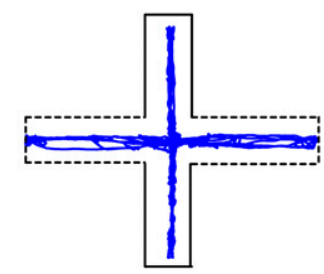

CS-US-ME
C

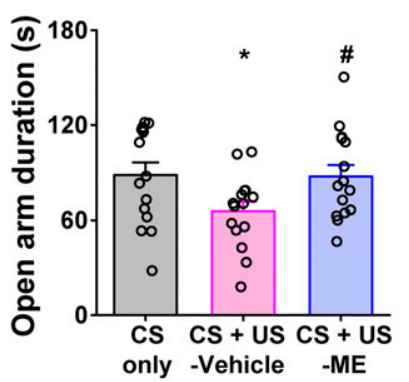

E

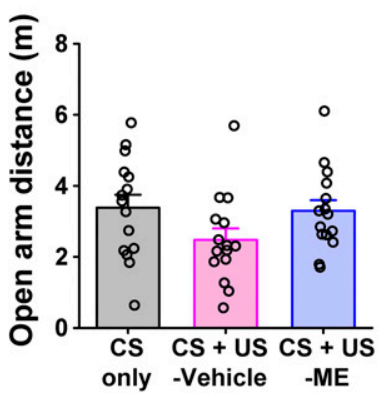

D

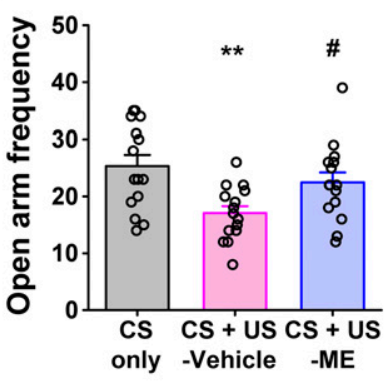

$\mathbf{F}$

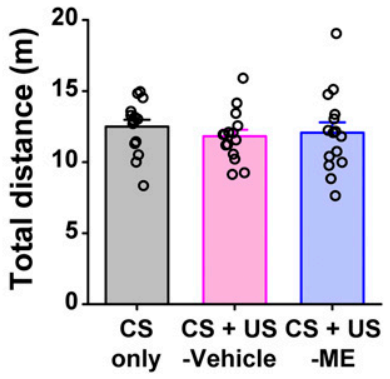

Fig. 6. Systemic administration of ME reduces the anxietyrelated behaviors. (A) Experimental protocol. (B) Example of EPM trajectories of animals with different treatments as indicated. (C-F) Pooled data of the time spent (C), and the number of entries (D), the distance (E) in the open arm, and the distance in the whole EPM (F). In each group, $n=15$ mice. $* P<0.05$; $* * P<0.01$, CS-only vs. CS-USvehicle; ${ }^{\#} P<0.05$, CS-US-vehicle vs. CS-US-ME, unpaired Student's $t$ test. and their expression is associated with fear conditioning (Heldt and Ressler, 2007) and anxiety-like behaviors (Tasan et al., 2011). Whether ME specifically targets the $\alpha 5$ $\mathrm{GABA}_{\mathrm{A}} \mathrm{Rs}$ to mediate its anxiolytic effects necessitates further investigation.

Extrasynaptic $\mathrm{GABA}_{\mathrm{A}} \mathrm{Rs}$ exhibit a high affinity for GABA (Bai et al., 2001; Semyanov et al., 2003); this mediates the currents that might require a continual presence of low levels of extracellular GABA (Semyanov et al., 2004) and necessitates the action potential-dependent spillover of the synaptic release of GABA. In addition, extrasynaptic $\mathrm{GABA}_{\mathrm{A}} \mathrm{Rs}_{\mathrm{s}}$ can open spontaneously in a ligand-independent way (McCartney et al., 2007; Wlodarczyk et al., 2013). In the present study, we blocked the action potential-mediated release with TTX. The ME-induced tonic current was unaltered by TTX (Fig. 1F; Fig. 2, A and B), which suggests that GABA spillover did not contribute significantly to this current. In the absence of ambient GABA, the tonic currents could arise from the constitutive activity of extrasynaptic $\mathrm{GABA}_{\mathrm{A}} \mathrm{Rs}$ (McCartney et al., 2007; Wlodarczyk et al., 2013). Coincidentally, it was reported that $\mathrm{ME}(\geq 100 \mu \mathrm{M})$ was able to directly activate endogenous and recombinant $\mathrm{GABA}_{\mathrm{A}} \mathrm{Rs}_{\mathrm{s}}$ (Ding et al., 2014), which indicates that ME can directly activate the extrasynaptic $\mathrm{GABA}_{\mathrm{A}} \mathrm{Rs}$ in CeA neurons regardless of the ambient level of GABA in the cerebral spinal fluid.

Anxiety disorders are highly prevalent (Kessler et al., 2005; Lieb, 2005) and can lead to depression and substance abuse (Ressler and Mayberg, 2007; Koob, 2009). The common therapeutics for anxiety include benzodiazepines, tricyclic antidepressants, monoamine oxidase inhibitors, and selective serotonin reuptake inhibitors; these have side effects that limit their clinical utility (Ravindran and Stein, 2010). For example, benzodiazepines, used for the treatment of anxiety disorders, are addictive and liable to abuse (Tan et al., 2010; Calixto, 2016), which makes their long-term usage limited; physical dependence and tolerance are also major concerns (Rudolph and Knoflach, 2011). Considering these limitations, a deeper understanding of anxiety control mechanisms in the mammalian brain and finding specific drugs are imperative.

With the rapid development of Chinese medicine targeting the $\mathrm{GABA}_{\mathrm{A}} \mathrm{Rs}$, finding a natural compound in traditional Chinese medicine with a high curative effect, safety for nerves, and low side effects will provide a novel perspective for the treatment of mental illness. ME is widely used in the daily life; 
A
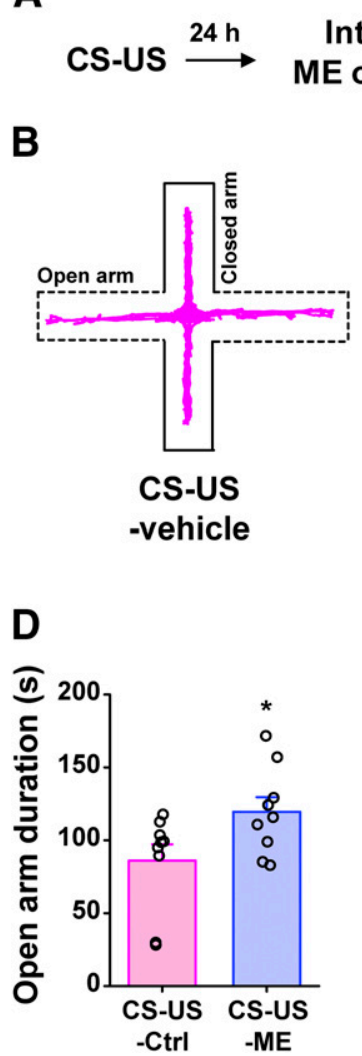

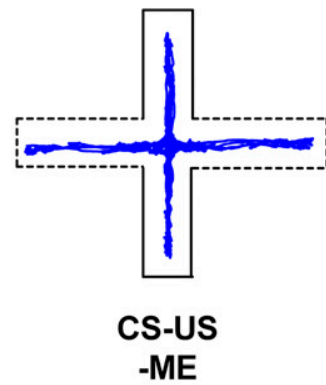

E

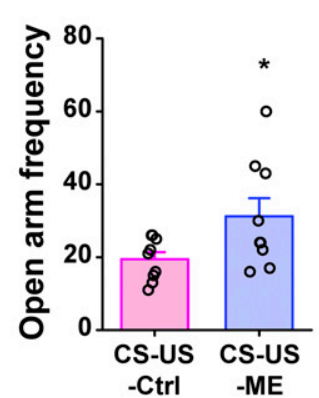

C

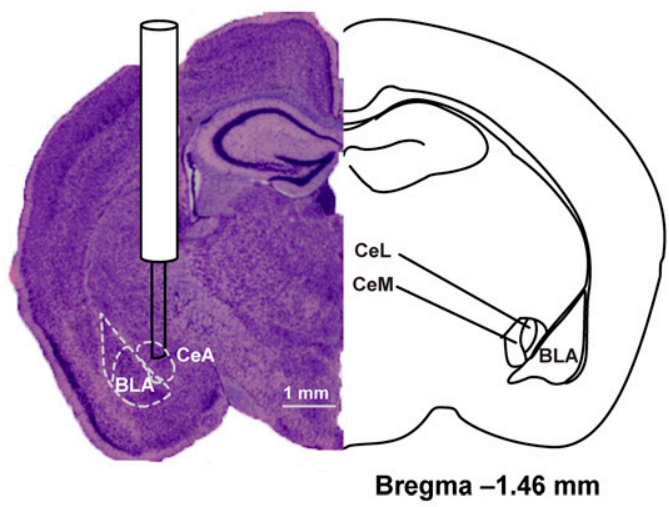

$\mathbf{F}$

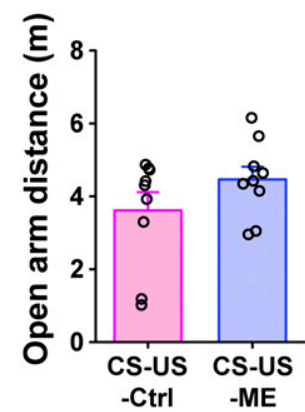

G

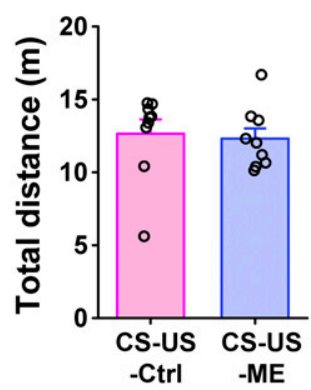

Fig. 7. ME reduces anxiety by potentiation of GABAergic inhibition in the CeA. (A) Experimental protocol. (B) Example of EPM trajectories of animals with different treatments as indicated. (C) Schematic illustrations of coronal sections demonstrating the location of the cannulas in the CeA. (D-G) Effects of intra-CeA infusion of ME on anxiety. Pooled data of the time spent (D) and number of entries in the open arms (E), the distance in the open arm (F), and the distance in the whole EPM (G). For each group, $n=9$ mice. N.S., not significant, $* P<0.05$, unpaired Student's $t$ test.

it is commonly found in cosmetics, soaps, and shampoos as a fragrance and also in jellies, baked goods, nonalcoholic beverages, chewing gum, and ice cream as a flavoring agent (Smith et al., 2002). Additionally, ME is a major active component isolated from Asiasari radix, a traditional herbal medicine, and other plants (De Vincenzi et al., 2000). The wide use of ME emphasizes its lack of prominent toxicity in humans.

Studies in rodents have shown that minimal ME within a dose range of $1-10 \mathrm{mg} / \mathrm{kg}$ body weight, is approximately 100-1000-fold of the anticipated human exposure to ME as a result of spiced and/or flavored food consumption, which does not pose a significant cancer risk or liver toxicity in a 2-year bioassay (Smith et al., 2002). However, at high concentrations $\mathrm{ME}$ can result in toxicity and even cancer risk with long-term use. Due to the lack of comprehensive pharmacokinetic characterization of $\mathrm{ME}$ in our current study, it is not clear yet what the expected dose would be for anxiolytic efficacy in humans.

Nevertheless, it is encouraging that $\mathrm{ME}$ as a modulator is capable of targeting GABAergic inhibition, especially the tonic form, in the $\mathrm{CeA}$, and producing a significant anxiolytic efficacy in the mouse model of pathologic anxiety while not impacting overall locomotor activity (Fig. 6, E and F; Fig. 7, F and G). We propose $\mathrm{ME}$ as a good candidate for the treatment of anxiety disorders and urge caution as well regarding its safety in humans. Additional mechanistic studies are needed in the future.

In addition to being a fly attractant (Tan and Nishida, 2012), ME also has antidepressive (Norte et al., 2005), anesthetic
(Sell and Carlini, 1976), antianaphylaxis (Shin et al., 1997), anticonvulsant (Sayyah et al., 2002), antinociceptive (Yano et al., 2006), and orexigenic (Zhu et al., 2018) effects. However, the underlying mechanisms of these functions are still actively being investigated. A previous study reported that $\mathrm{ME}$ inhibited the voltage-gated sodium Nav1.7 channels, which underlies its antinociceptive and anesthetic actions (Wang et al., 2015). Additionally, ME is an agonist of the TRPA1 channel (Moon et al., 2015); blockade or genetic ablation of the TRPA1 channel decreases anxietylike behaviors in mice (de Moura et al., 2014; Lee et al., 2017). Therefore, ME activation of TRPA1 channels may increase anxiety-like behaviors in mice. In our study, we found that integrated pharmacologic function of $\mathrm{ME}$ was anxiolytic in animal behaviors, further confirming that ME reduces anxiety primarily through the potentiation of GABAergic inhibition in the CeA.

\section{Conclusion}

We have shown that ME reduces the anxiety-related behaviors by increasing both tonic and phasic forms of GABAergic inhibition in CeA neurons. Our present findings also demonstrate the cellular mechanism underlying the anti-anxiety efficacy of ME via potentiation of GABAergic inhibition in the CeA, which implicates novel treatment strategies for anxiety disorders. 


\section{Acknowledgments}

We would like to thank Tian-Le Xu (Shanghai Jiao Tong University School of Medicine, People's Republic of China) for providing us with experimental facility to this work.

\section{Authorship Contributions}

Participated in research design: Ge, W.-G. Li, F. Li.

Conducted experiments: Liu, Fan, Deng, Zhu, Yan.

Performed data analysis: Liu, W.-G. Li.

Wrote or contributed to the writing of the manuscript: Liu, W.-G. Li.

\section{References}

Bai D, Zhu G, Pennefather P, Jackson MF, MacDonald JF, and Orser BA (2001) Distinct functional and pharmacological properties of tonic and quantal inhibitory postsynaptic currents mediated by gamma-aminobutyric acid(A) receptors in hippocampal neurons. Mol Pharmacol 59:814-824.

Botta P, Demmou L, Kasugai Y, Markovic M, Xu C, Fadok JP, Lu T, Poe MM, Xu L, Cook JM, et al. (2015) Regulating anxiety with extrasynaptic inhibition. Nat Neurosci 18:1493-1500.

Brickley SG and Mody I (2012) Extrasynaptic GABA(A) receptors: their function in the CNS and implications for disease. Neuron 73:23-34.

Calixto E (2016) GABA withdrawal syndrome: GABAA receptor, synapse, neurobiological implications and analogies with other abstinences. Neuroscience 313:57-72.

Davis M, Walker DL, Miles L, and Grillon C (2010) Phasic vs sustained fear in rats and humans: role of the extended amygdala in fear vs anxiety. Neuropsychopharmacology 35:105-135.

de Moura JC, Noroes MM, Rachetti VdeP, Soares BL, Preti D, Nassini R, Materazzi S, Marone IM, Minocci D, Geppetti P, et al. (2014) The blockade of transient receptor potential ankirin 1 (TRPA1) signalling mediates antidepressant- and anxiolytic-like actions in mice. $\mathrm{Br} J$ Pharmacol 171:4289-4299.

De Vincenzi M, Silano M, Stacchini P, and Scazzocchio B (2000) Constituents of aromatic plants: I. Methyleugenol. Fitoterapia 71:216-221.

Ding J, Huang C, Peng Z, Xie Y, Deng S, Nie YZ, Xu TL, Ge WH, Li WG, and Li F (2014) Electrophysiological characterization of methyleugenol: a novel agonist of GABA(A) receptors. ACS Chem Neurosci 5:803-811.

Etkin A, Prater KE, Schatzberg AF, Menon V, and Greicius MD (2009) Disrupted amygdalar subregion functional connectivity and evidence of a compensatory network in generalized anxiety disorder. Arch Gen Psychiatry 66:1361-1372.

Farrant M and Nusser Z (2005) Variations on an inhibitory theme: phasic and tonic activation of GABA(A) receptors. Nat Rev Neurosci 6:215-229.

Heldt SA and Ressler KJ (2007) Training-induced changes in the expression of GABAA-associated genes in the amygdala after the acquisition and extinction of Pavlovian fear. Eur J Neurosci 26:3631-3644.

Herman MA, Contet C, Justice NJ, Vale W, and Roberto M (2013) Novel subunitspecific tonic GABA currents and differential effects of ethanol in the central amygdala of CRF receptor-1 reporter mice. J Neurosci 33:3284-3298.

Houser CR and Esclapez M (2003) Downregulation of the alpha5 subunit of the GABA(A) receptor in the pilocarpine model of temporal lobe epilepsy. Hippocampus 13:633-645.

Huang C, Li WG, Zhang XB, Wang L, Xu TL, Wu D, and Li Y (2013) $\alpha$-asarone from Acorus gramineus alleviates epilepsy by modulating A-type GABA receptors. Neuropharmacology 65:1-11.

Kessler RC, Berglund P, Demler O, Jin R, Merikangas KR, and Walters EE (2005) Lifetime prevalence and age-of-onset distributions of DSM-IV disorders in the National Comorbidity Survey Replication [published correction appears in Arch Gen Psychiatry (2005) 62:768]. Arch Gen Psychiatry 62:593-602.

Kim MJ, Loucks RA, Palmer AL, Brown AC, Solomon KM, Marchante AN, and Whalen PJ (2011) The structural and functional connectivity of the amygdala: from normal emotion to pathological anxiety. Behav Brain Res 223:403-410.

Koob GF (2009) Brain stress systems in the amygdala and addiction. Brain Res 1293:61-75.

Lee KI, Lin HC, Lee HT, Tsai FC, and Lee TS (2017) Loss of transient receptor potential ankyrin 1 channel deregulates emotion, learning and memory, cognition, and social behavior in mice. Mol Neurobiol 54:3606-3617.

Lieb R (2005) Anxiety disorders: clinical presentation and epidemiology. Handb Exp Pharmacol 169:405-432.

McCartney MR, Deeb TZ, Henderson TN, and Hales TG (2007) Tonically active GABAA receptors in hippocampal pyramidal neurons exhibit constitutive GABAindependent gating. Mol Pharmacol 71:539-548.

Millan MJ (2003) The neurobiology and control of anxious states. Prog Neurobiol 70 83-244.

Moon H, Kim MJ, Son HJ, Kweon HJ, Kim JT, Kim Y, Shim J, Suh BC, and Rhyu MR (2015) Five hTRPA1 agonists found in indigenous Korean mint, Agastache rugosa. PLoS One 10:e127060.
Norte MC, Cosentino RM, and Lazarini CA (2005) Effects of methyl-eugenol administration on behavioral models related to depression and anxiety, in rats. Phytomedicine 12:294-298.

Pellow S, Chopin P, File SE, and Briley M (1985) Validation of open:closed arm entries in an elevated plus-maze as a measure of anxiety in the rat. $J$ Neurosci Methods 14:149-167.

Ravindran LN and Stein MB (2010) The pharmacologic treatment of anxiety disorders: a review of progress. J Clin Psychiatry 71:839-854.

Ressler KJ and Mayberg HS (2007) Targeting abnormal neural circuits in mood and anxiety disorders: from the laboratory to the clinic. Nat Neurosci 10:1116-1124.

Roberto M, Gilpin NW, O'Dell LE, Cruz MT, Morse AC, Siggins GR, and Koob GF (2008) Cellular and behavioral interactions of gabapentin with alcohol dependence. J Neurosci 28:5762-5771.

Rudolph U and Knoflach F (2011) Beyond classical benzodiazepines: novel therapeutic potential of GABAA receptor subtypes. Nat Rev Drug Discov 10:685-697.

Sayyah M, Valizadeh J, and Kamalinejad M (2002) Anticonvulsant activity of the leaf essential oil of Laurus nobilis against pentylenetetrazole- and maximal electroshock-induced seizures. Phytomedicine 9:212-216.

Sell AB and Carlini EA (1976) Anesthetic action of methyleugenol and other eugenol derivatives. Pharmacology 14:367-377.

Semyanov A, Walker MC, and Kullmann DM (2003) GABA uptake regulates cortical excitability via cell type-specific tonic inhibition. Nat Neurosci 6:484-490.

Semyanov A, Walker MC, Kullmann DM, and Silver RA (2004) Tonically active GABA A receptors: modulating gain and maintaining the tone. Trends Neurosci 27:262-269.

Shen Q, Lal R, Luellen BA, Earnheart JC, Andrews AM, and Luscher B (2010) gamma-Aminobutyric acid-type A receptor deficits cause hypothalamic-pituitaryadrenal axis hyperactivity and antidepressant drug sensitivity reminiscent of melancholic forms of depression [published correction appears in Biol Psychiatry (2012) 72:978]. Biol Psychiatry 68:512-520.

Shigetomi E, Tong X, Kwan KY, Corey DP, and Khakh BS (2011) TRPA1 channels regulate astrocyte resting calcium and inhibitory synapse efficacy through GAT-3. Nat Neurosci 15:70-80.

Shin BK, Lee EH, and Kim HM (1997) Suppression of L-histidine decarboxylase mRNA expression by methyleugenol. Biochem Biophys Res Commun 232:188-191.

Smith RL, Adams TB, Doull J, Feron VJ, Goodman JI, Marnett LJ, Portoghese PS, Waddell WJ, Wagner BM, Rogers AE, et al. (2002) Safety assessment of allylalkoxybenzene derivatives used as flavouring substances-methyl eugenol and estragole. Food Chem Toxicol 40:851-870.

Tan KH and Nishida R (2012) Methyl eugenol: its occurrence, distribution, and role in nature, especially in relation to insect behavior and pollination. J Insect Sci 12:56.

Tan KR, Brown M, Labouèbe G, Yvon C, Creton C, Fritschy JM, Rudolph U, and Lüscher C (2010) Neural bases for addictive properties of benzodiazepines. Nature 463:769-774.

Tasan RO, Bukovac A, Peterschmitt YN, Sartori SB, Landgraf R, Singewald N, and Sperk G (2011) Altered GABA transmission in a mouse model of increased trait anxiety. Neuroscience 183:71-80.

Tovote P, Fadok JP, and Lüthi A (2015) Neuronal circuits for fear and anxiety. Nat Rev Neurosci 16:317-331.

Tye KM, Prakash R, Kim SY, Fenno LE, Grosenick L, Zarabi H, Thompson KR, Gradinaru V, Ramakrishnan C, and Deisseroth K (2011) Amygdala circuitry mediating reversible and bidirectional control of anxiety. Nature 471:358-362.

Wang ZJ, Tabakoff B, Levinson SR, and Heinbockel T (2015) Inhibition of Nav1.7 channels by methyl eugenol as a mechanism underlying its antinociceptive and anesthetic actions. Acta Pharmacol Sin 36:791-799.

Wlodarczyk AI, Sylantyev S, Herd MB, Kersanté F, Lambert JJ, Rusakov DA, Linthorst AC, Semyanov A, Belelli D, Pavlov I, et al. (2013) GABA-independent GABAA receptor openings maintain tonic currents. J Neurosci 33:3905-3914.

Yano S, Suzuki Y, Yuzurihara M, Kase Y, Takeda S, Watanabe S, Aburada M, and Miyamoto K (2006) Antinociceptive effect of methyleugenol on formalininduced hyperalgesia in mice. Eur J Pharmacol 553:99-103.

Zhang LH, Gong N, Fei D, Xu L, and Xu TL (2008) Glycine uptake regulates hippocampal network activity via glycine receptor-mediated tonic inhibition. Neuropsychopharmacology 33:701-711.

Zhu T, Yan Y, Deng S, Liu YM, Fan HR, Ma B, Meng B, Mei B, Li WG, and Li F (2018) Methyleugenol counteracts anorexigenic signals in association with GABAergic inhibition in the central amygdala. Neuropharmacology 141:331-342.

Address correspondence to: Dr. Fei Li, Developmental and Behavioral Pediatric Department, Ministry of Education-Shanghai Key Laboratory for Children's Environmental Health, Shanghai Institute for Pediatric Research, Xinhua Hospital Affiliated Shanghai Jiao Tong University School of Medicine, Shanghai 200092, People's Republic of China. E-mail: feili@shsmu.edu.cn; or Dr. Wei-Guang Li, Collaborative Innovation Center for Brain Science, Department of Anatomy and Physiology, Shanghai Jiao Tong University School of Medicine, Shanghai 200025, People's Republic of China. E-mail: wgli@shsmu.edu.cn 